\title{
COMORBIDITIES ASSOCIATED WITH MUSCULOSKELETAL PAIN IN A RURAL COMMUNITY IN MATO
} GROSSO DO SUL, BRAZIL

Marcelo Hitoshi Kinashi (HU-UFGD, Dourados, MS, Brasil), Marcia Midori Shinzato (UFGD, Dourados, MS, Brasil)

\section{BACKGROUND}

Musculoskeletal (MSK) diseases reduce physical function and increase the risk of developing other chronic condition. It is described that multimobidities increase with age and very commonly include MSK condition. Thus, this study aimed to observed the relationship of most common chronic diseases and MSK pain.

\section{MATERIALS AND METHODS}

This was a cross-sectional, observational study in which randomly selected subjects over 15 years old from a rural community were administered the questionnaire of the Program Oriented Community for the Control of Rheumatic Diseases. We also collected data of self-reported chronic diseases and carried out standardized measurement of patients' height, weight and waist circumference. Obesity was defined as body mass index $\geq 30$ and central obesity as waist circunference $\geq 102$ for males and $\geq 88$ for females. Student $t$ or qui-squared test were used to compare those with and without MSK pain, two-tailed $p<0.05$ were considered statistically significant. Age was categorized in three groups:>15 $\leq 19$ (group 1), 20-59 (group 2 ) and $\geq 60$ years old (group 3 ). Each group were subcategorize in male (M) and female (F).

\section{RESULTS}

The study included 374 subjects; mean age 46,78 (18,34), 56.95\% were women. MSK pain were reported by $66,31 \%$. Individuals with MSK pain were older than those without MSK pain, 48.80 (18.05) vs 42.80 (18.31) years, respectively , $p=0.003$. More patients with MSK pain were female, $149 / 248(60.08 \%)$ vs $65 / 126$ (51.59\%), $p=0.14$. Prevalence of MSK pain in group 1 was $11 / 27$ (40.74\%), in group 2: $163 / 246$ $(66.26 \%)$ and in group 3: $74 / 101$ (73.27\%). ). Most frequent comorbidities were: obesity $45.56 \%$, hypertension (41.14\%), depression and/or anxiety (25.40\%), dyslipidemia (19.35\%), diabetes (17.74\%), hypothyroidism (10.89\%). In the group $2 \mathrm{M}$ : obesity was observed in 23/64 (35.94\%) with MSK pain and in $6 / 39(15.38 \%)$ without MSK pain, $p=0.043$. Whereas central obesity was observed in $27 / 64(42.19 \%)$ and $6 / 39(15.38 \%)$ respectively, $p=0.0021$. In the group 2 for women $(F)$, we observed significant difference for central obesity when the group without pain were compared with the group with severe/very severe pain: $21 / 44(47.72 \%)$ and $26 / 36(72.22 \%), p=0.047$. The presence of the other comorbidities was similar between the groups

\section{CONCLUSION}

Obesity and central obesity were correlated with MSK pain in men from 20 to 59 years old.

Central obesity was associate with MSK pain in women from 20-59 with more severe pain. 